\title{
Tsao Yves, Les Travailleurs chinois recrutés par la France pendant la Grande Guerre
}

\section{Ralph Schor}

\section{(2) OpenEdition}

10 Journals

Édition électronique

URL : https://journals.openedition.org/remi/14031

DOI : $10.4000 /$ remi. 14031

ISSN : $1777-5418$

Éditeur

Université de Poitiers

\section{Édition imprimée}

Date de publication : 1 décembre 2019

Pagination : 307-309

ISBN : 979-10-90426-65-8

ISSN : 0765-0752

Référence électronique

Ralph Schor, "Tsao Yves, Les Travailleurs chinois recrutés par la France pendant la Grande Guerre ", Revue européenne des migrations internationales [En ligne], vol. 35 - n³ 3 et 4 | 2019, mis en ligne le 01 décembre 2019, consulté le 15 avril 2022. URL : http://journals.openedition.org/remi/14031 ; DOI : https://doi.org/10.4000/remi.14031

Ce document a été généré automatiquement le 15 avril 2022.

(C) Université de Poitiers 


\title{
Tsao Yves, Les Travailleurs chinois recrutés par la France pendant la Grande Guerre
}

\author{
Ralph Schor
}

\section{RÉFÉRENCE}

Tsao Yves (2018) Les Travailleurs chinois recrutés par la France pendant la Grande Guerre, Aix-en-Provence, Presses universitaires de Provence, 364 p., ISBN : 979-10-320-0155-4

1 Pendant la Grande Guerre, les besoins de main-d'œuvre conduisirent les pays de l'Entente à largement recourir aux travailleurs étrangers et coloniaux. Quelque 130000 Chinois furent ainsi introduits en France. Environ 90000 d'entre eux relevaient de l'autorité britannique; près de 40000 autres, débarqués à Marseille à partir d'août 1916, après avoir été recrutés par une mission dépêchée en Chine par le ministère de la Guerre, se trouvaient placés sous l'autorité française. C'est à l'étude de ce contingent que s'est consacré Yves Tsao.

2 L'auteur montre d'abord combien les usines et les chantiers français, dépeuplés par la mobilisation, avaient besoin de bras, ce qui rendait vaines les craintes éprouvées dans de nombreux milieux par l'arrivée d'hommes inconnus et différents. Quant aux responsables chinois, ils voulaient se rapprocher des pays de l'Entente pour faire obstacle aux visées impérialistes du Japon sur leur pays ; ils espéraient secondairement que leurs compatriotes pourraient s'initier aux méthodes modernes de production et ainsi, à leur retour, servir au développement économique de la patrie. Aussi des contrats furent-ils signés entre les deux parties, accords prévoyant notamment la nonparticipation aux opérations militaires, la gratuité des voyages, du logement, de la nourriture, des soins médicaux et l'égalité des salaires avec les Français.

3 Les travailleurs recrutés, parfois avec le concours de la pègre chinoise, étaient principalement de jeunes paysans souvent illettrés, des ouvriers, des soldats et 
quelques étudiants curieux de connaître la France. Le voyage maritime, compliqué et périlleux en raison de la guerre sous-marine durait en moyenne cinquante-trois jours, parfois soixante-dix-huit. Nombre de Chinois moururent en route du fait des torpillages, de maladies, d'accidents, de suicide parfois. Beaucoup désertaient au cours des escales.

4 Arrivés en France, les Chinois, vus comme inassimilables en raison de leur « infériorité raciale ", étaient étroitement contrôlés et soumis à un statut militaire impliquant une discipline stricte. Ils étaient distribués dans les établissements publics et privés, les usines de guerre, les transports, les services forestiers et routiers des armées. Ces hommes étaient installés dans des camps souvent clos et gardés. Isolés des populations locales, souffrant de l'inconfort du logement, mal nourris et mal vêtus, s'appuyant sur des interprètes plus ou moins compétents et honnêtes, les travailleurs chinois vécurent dans des conditions précaires. Les bombardements allemands, les accidents du travail, les maladies, surtout la tuberculose et les pneumonies, causèrent dans leurs rangs un millier de décès.

Vus souvent comme fourbes, féroces, primitifs, les Chinois se heurtèrent à l'hostilité des populations locales et aux refus de vente. Les syndicats, surtout le principal d'entre eux, la CGT, largement pénétrés par la xénophobie, voyaient les nouveaux venus comme des concurrents et des briseurs de grève. Les organisations françaises ne dénonçaient pas les violences dont les Chinois étaient victimes, les entorses aux contrats, les mauvaises conditions de vie et de travail imposées aux immigrés. Aussi ces derniers répliquaient-ils eux-mêmes par des violences et des grèves. Les rixes impliquant parfois plusieurs centaines d'hommes n'étaient pas rares, surtout avec les autres contingents immigrés comme les Maghrébins. Ces combats illustraient la volonté de solidarité et de cohésion du groupe, mais aussi sa propre xénophobie à l'égard des autres travailleurs. Les Chinois tombaient parfois dans la délinquance de droit commun, principalement pour des questions d'argent et de mœurs.

Une fois la guerre terminée, les Chinois qui n'étaient pas arrivés au terme de leurs contrats furent souvent dirigés vers les ports et les régions libérées qui, dévastées par les combats, devaient être remises en état. La documentation permet à l'auteur de qualifier les relations avec les populations locales de "cohabitation impossible" (p. 271). Les vols, les viols, les assassinats furent enregistrés en nombre. Aussi les autorités françaises hâtèrent-elles le rapatriement des Chinois à partir du 31 décembre 1920. Restèrent en France quelque 3000 hommes ayant échappé à la surveillance de leurs gardiens ou demandés par certains employeurs, ce qui montrait que, contrairement à diverses déclarations xénophobes de l'époque, l'expérience ne se révélait pas totalement négative. Quelques-uns s'installèrent à Paris, près de la gare de Lyon, dans l'îlot Chalon, premier quartier chinois de la capitale.

7 Yves Tsao qui ne connaît pas langue chinoise a travaillé exclusivement sur les sources françaises, fort riches. Un dépouillement des sources «célestes» ouvrirait probablement d'autres perspectives, par exemple sur les loisirs et la vie sentimentale des immigrés, thèmes presque absents de l'étude. Cependant, telle quelle, l'analyse, méthodique et scrupuleuse, se révèle intéressante. Elle fournit de nombreux renseignements sur la règlementation, les rémunérations, les transferts d'argent, l'autonomisation des acteurs de terrain, le principe de l'égalité des coûts par lequel les employeurs purent se soustraire à l'égalité salariale prévue initialement, sur les comportements des groupes mis en présence. Cet ouvrage ne révolutionne pas la 
connaissance de l'immigration lointaine en temps de guerre, mais il en précise bien les contours.

\section{AUTEURS}

\section{RALPH SCHOR}

Historien, Professeur émérite, Université de Nice-Sophia-Antipolis 